\title{
Addiction or existential malaise? Same or different?
}

\author{
Review of:-
}

\section{"The Globalisation of Addiction: a study in poverty of the spirit." Bruce K.Alexander. Oxford: Oxford University Press (2008)}

This is, without doubt, the most intriguing and painstaking book on addiction I have read for many years. If this review is a little longer that is usual, it's because this text appears to represent the culmination of some 35 years work in the addictions by a major scholar, and is a story of personal development as well as a new and iconoclastic account of addiction.

Bruce Alexander is still probably best remembered (doubtless to his chagrin) for the 'rat park' studies, (e.g. Alexander et al; 1978, 1981) in which rats who relentlessly self administered drugs in the hostile environment of a Skinner box showed (under a variety of experimental conditions) a preference for food and water without drugs when placed in more naturalistic 'rat park' environments. Naturally, as a good scientist, one should never generalise from these kinds of results to human subjects, nor speculate that people become addicted due to the environments in which they live on the basis of animal studies; nor suggest that therefore given different living conditions people would cease to be addicted. But it's tempting. Bruce Alexander appears, however (to some degree, and in a particular sense) to have broken the traditional academic fetters and grasped this nettle; and I cannot help but suspect that the rat studies planted the seed for him, as they certainly did for me! The result is a riveting examination of contemporary Western society, and an indictment of capitalism and the free-market economy which is as close to being neo-Marxist as one could go without being one. It is as much a condemnation of 'Western civilisation' as an account of addiction.

I last met Bruce about three years ago at the 'Unhooked Thinking' conference in Bath. He had already written an invited editorial for this Journal, because I noted that in his recent writings of that time he was 'moving on' from deterministic science to becoming a radical political philosopher who expressed views on contemporary society that I had occasionally ruminated on myself, but only at a superfical level, over a pint in the pub. At Bath, in conversation, he more or less disowned his own work with the rats, dismissing them as I recall as rather trivial; which they are not. He also went on to dismiss whole areas of psychology as misconceived and philosophically bankrupt, a subject that had lost its way; and once again these views were increasingly reflective of my own. At the 
conference, Bruce gave a talk on St. Augustine and sex addiction, which had many of us baffled. Now I know why.

"The Globalisation of Addiction" is scholarly, meticulously researched, passionately critical of the free-market economy, biased, speculative, selective, and quite wonderful. It is basically an indictment of the capitalist free-market ethic that is being with increasing rapidity imposed on the rest of the world. In order to work, this free-market philosophy requires as its fundamental principle the 'dislocation' of people from each other, from society and from any semblance of culture, since the basic requirement of capitalism/free-markets is that people shall compete with each other as individuals for economic and material advantage ceaselessly and without hindrance; something which is impeded by history, culture and a sense of belonging and collective purpose/identity. These things have been noted before, but no-one thus far has extended the argument in a way that casts a vast range of pursuits at all levels of society, ranging from a) 'overwhelming' street-level poverty-related drug use on the one hand, to b) the 'overwhelming' pursuit of wealth, goods and business 'success' on the other, as 'addictions'. Specifically, the argument is that 'dislocation', or 'loss of psychosocial intergration', leads people to adopt all sorts of substitute adaptive behaviours. These substitute adaptive behaviours, which can be of any kind, become 'overwhelming' for increasing numbers of people, leading to harm directly or indirectly to self and/or society, and therefore qualify as 'addictions' according to certain definitions offered near the start of the book. The whole argument is outlined in the most beautiful literate prose, and it takes a little while before you realise that the underlying message, and the repeated historical references to the decline and fall of past civilisations, is truly apocalyptic.

It has to be said that the argument is perhaps stretched a bit thin in places. Every important problem of society, it is argued, basically boils down to 'dislocation', and whatever goes wrong or has gone wrong in the past, from Plato to Putin, is interpreted as 'dislocation' where other more focussed concepts might be employed that require less interpretation and/or translation. Nonetheless, the argument is supported by a massive breadth of reference, scientific and non-scientific; historical and contemporary, and the result is hugely impressive. (I was reminded of Tajfel's (1971) classic studies showing how groups of middle-class UK school-children would react competitively and exploitatively towards other groups of children about whom they knew nothing at all, other than that they were not members of their group. Tajfel speculated about society along similar lines to Alexander, though in more tentative tones; but never mentioned addiction).

There are two points over which I personally struggle. Firstly, Alexander gives insufficient recognition to the functional role of the addiction label in today's litigious and politically-correct society. Orford (1985) made the point in his classic text that 'addiction' has no meaning until someone or something puts pressure on you to stop doing something; so given the extensive reference to Jim Orford's work, I was disappointed that this important point was virtually lost sight of. Secondly, the definition

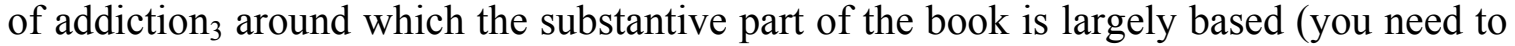
read the book to find out about addiction ${ }_{1,2,3}$ and 4 ) permits the extension of the 
'addiction' label into territory where, in my opinion, linguistic function becomes paramount and compulsion (however defined) becomes minimal. Anything can be an addiction. That's the bit I still have a big problem with.

I also think that casting a major part of the problems created by free markets in terms of the two principle concepts, 'dislocation' and 'addiction', shows a degree of tunnel vision, as if attempting to stop up a number of holes that globally vary substantially in shape and size with just two one-size-fits-all plugs. As a consequence, the solutions he offers seem more like acts of faith, tantamount to reinventing the whole economic and social bases for our society on the one hand, and encouraging a variety of non-revolutionary community action projects, some of which have been tried before, on the other. The key to change, morover, is 'determined social action' ( see pages 388-392) of a type that I think is unlikely to come about. Alexander envisages that increasingly powerful societal movements, characterised by social responsibility, self denial and altruism on the part of people driven by long-term goals, could somehow arise spontaneously. This from a socially bankrupt 'democracy' within which people are explicity taught to be egocentric, materialist, and driven solely by short-term personal satisfactions, which at the end of the day are the things they vote for. Glorious though his visions are I find it hard to imagine how the change he advocates would come about, or how his suggestions would ever feature large on any current political or social agenda of any shade unless (as he indeed suggests on page 339 , amongst other optional catastrophes) we have, say, a nuclear war first to bring us to our senses. So I'm not optimistic about the proposed solutions. Part of the problem is that I can't tell whether Alexander is trying to solve the problems of globalisation in general or the problems of addiction (however defined) in particular, because for him they are quite inseperable. Addiction has no dynamics independent of global dislocation.

Alexander's vision for global society is, at this point, terrifying and apocalyptic, and he may be right. However whilst I agree with the damning critique of the society we've built for ourselves and increasingly imposed on everybody else, for me the addiction issue is more prosaic. The proposed causal link between dysfunctional politics at a global level and addiction to drugs on the streets of Blackhill needs a stronger evidence base. To use Alexander's own terminology (and insofar as I believe in the addiction concept at all, other than as a functional attribution), I believe that addiction to drugs in deprived inner city areas $\left(\right.$ addiction $\left._{1}\right)$ and general existential malaise $\left(\right.$ addiction $_{3)}$ are different, socialclass-related and discrete things with different causal dynamics; and perhaps that's the main point. To propose that a Porsche-driving executive with a cover-girl wife and a villa in Spain, devoted to the accumulation of wealth, is confronting the same problem as an out-of-work miner with a dysfunctional family and lung disease, devoted to the consumption of alcohol, just seems so unreasonable.

Should you read this book? Oh yes. No doubt about it. On a broader front, this is the most fascinating and disturbing book on addictions for a very, very, long time. Apart from anything else, it's a great read. It's also an account of development and change within an individual person, from successful academic, scientist and empirical researcher into something more spiritual. Whether that is ultimately a beneficial change at other than a 
personal level, I cannot say, as I still regard the rat-park studies as classics of their type. Whatever conclusion you may draw, the passionate style reveals a man who believes these ideas from the top of his head to the tips of his toes. He hasn't written this just to pay the mortgage or to do well in the next research assessment exercise (see pages 386388 for his comments on the economic subversion of Universities). The book is bound to become a classic. You don't have to agree with it; and personally I think (and fervently hope) that he's too pessimistic, and that his basically one-dimensional analysis of the roots of dysfunctional social behaviour ignores important complexities. But if you don't agree, you do have to argue against it, and it's not that easy.

Intense beyond belief, highly original, highly thought provoking, and highly recommended. Warts and all, this is one of the addiction texts of the decade.

\section{$\underline{\text { References. }}$}

ALEXANDER, B.K., COAMBS, R.B., and HADAWAY, P.F. (1978) The effect of housing and gender on morphine self-administration in rats. Psychopharmacology 58, 175-179.

ALEXANDER, B.K., BEYERSTEIN, B.L., HADAWAY, P.F. and COAMBS, R.B. (1981) Effect of early and late colony housing on oral ingestion of morphine in rats. Pharmacology, Biochemsitry and Behaviour, 15, 571-576.

ORFORD, J (1975) Excessive Appetites: a Psychological View of Addictions. Chichester: Wiley

TAJFEL, H (1971) Experiments in Intergroup Discrimination. In Contemporary Psychology: Readings from the Scientific American (416-422) San Francisco: Freeman and Co.

John B.Davies

Centre for Applied Social Psychology

University of Strathclyde

Glasgow 